\title{
Vehicles Maintenance Workshops Layout and its Management to Reduce Noise Pollution and Improve Maintenance Quality
}

\author{
Hesham Almomani ${ }^{1 *}$, Naser Almutairi ${ }^{2}$ \\ Department of Industrial Engineering, Faculty of Engineering, the Hashemite University, Jordan \\ Received: 06/01/2020 \\ Accepted: 13/04/2020 \\ Published: 20/09/2020
}

\begin{abstract}
Most of vehicle maintenance in Arab world and Jordan is random with low share of management control, this system making maintenance of vehicles going on with low reliability. The need for managing maintenance operations and workshops layout of maintenance workshops and reduce noise pollution is crucial. The aim of this paper is to show the importance of maintenance management and vehicles maintenance workshops management and workshops layout in reduce noise pollution and improving the operations of maintenance of automobiles. The observations and collecting data about status of maintenance of vehicles workshops in Jordan is used here. Data and figures about the current status of some studied workshop is presented here. A suggestion for new and multi alternatives for workshop layouts are analyzed depending on Mean Time TO repair (MTTR). It is found that improving management methods and maintenance workshops layout will reduce noise pollution and improve the maintenance operations type and decreasing MTTR for failures. MTTR, costs and quality of maintenance are important factors affected by the maintenance of vehicles workshop layout, as the layout is arranged in good and flexible way the system becomes better and MTTR decreases.
\end{abstract}

Keywords: Maintenance, Workshops, Layout vehicles, MTTR

\section{Introduction}

Automobiles need maintenance from time to time. Like human beings are required to keep hygiene, in a similar fashion motors additionally want to be stored clean. Automobiles have to run on soiled roads and in a polluted environment. They run on uneven roads with potholes and different obstructions, and are consequently subjected to masses which injury them. Therefore, there is a want for normal preservation and servicing of automobiles, which is typically carried out in auto workshops or auto provider stations. Every new car comes with a car protection manual. The proprietor of the automobile is anticipated to examine and use this manual, as it mentions car preservation pointers at some stage in driving. It has been observed that after getting an auto or vehicle, the proprietors do no longer care a good deal about a normal vehicle or automobile maintenance. Even if the proprietors often carrier their vehicle, the automobile protection recommendations given in the automobile preservation guide will increase the sturdiness or lifestyles of the automobile to a super extent. Vehicle protection and servicing is carried out when the car completes sure kilometers on its ordinary going for walks or when the car does no longer provide appropriate performance. It is counseled that the car proprietors raise out ordinary and periodical exams on their vehicle, some of which are referred to under $[1,2]$.

\section{Daily Inspection (DI)}

It is the accountability of a driver or proprietor of an automobile to lift out the following inspection and exams daily, before beginning the engine, to keep away from any kind of breakdown on the road. (i) Check tire stress in all the tires visually or with the aid of hitting the tire wall with the assist of a stone and decide the sound (ii) Check the radiator's coolant degree (iii) Check the fan belts for looseness (iv) Check the degree of engine oil (v) Check the windscreen, rear-view reflect and rear-window glass for their cleanliness [1].

\section{Maintenance Check-up}

When one plans a lengthy distance travel, it is imperative to elevate out a hobbies check-up. One need to examine the automobile renovation guide for clarity. Some necessary check-ups

are accomplished for higher maintenance. (i) Topping of oil level; (ii) Proper tension of belt; (iii) Battery for cleanliness and level of electrolyte (add only distilled water for topping of electrolyte water); (iv) Brakes; (v) Topping up of coolant, if required, in the coolant reservoir; (vi) Checking the serviceability of cooling system hoses; (vii) Proper tyre inflation pressure; and (viii) Air conditioning.

\section{Tips to Extend the Life of a Vehicle Care}

and protection maintain the automobile operating in correct co ndition. The following tips assist in higher renovation of a vehicle, and ought to be discovered in daily life. (i) drive the

Corresponding author: Hesham Almomani, Department of Industrial Engineering, Faculty of Engineering, the Hashemite University. E-mail: heshamalmomani@hu.edu.jo 
vehicle with care every day; (ii) be patient during the accident or breakdown of a vehicle, call helpline number of vehicle; (iii) buy petrol from reputed and trustworthy service stations; (iv) do not fill up fuel if your vehicle is parked around an oil tanker; (v) Car keychain should be light; (vi) Preserve the car during long-term storage (vii) clean the inside too; (viii) clean dash gauges carefully; (ix) preserve door and window seals; (x) do not carry too much load (xi) use upholstery cleaners on soiled seats; (xii) place a towel under baby seats; (xiii) protect car paint from the sun by parking it in a spot that is out of direct sunlight. You can also apply high-quality wax as it prevents sun damage to car paint from ultraviolet radiation (xiv) Maintain proper tire inflation; (xv) Check for uneven wear; (xvi) Rotate your tyres; (xvii) Get wheel alignment checked; (xviii) top off brake fluid; (xix) care for anti-lock brakes; (xx) check engine oil at every other fill-up; (xxi) change oil frequently; (xxii) do not mix coolants; (xxiii) avoid hose hassles; (xxiv) check drivebelt tension; (xxv) clean your engine; (xxvi) keep the AC functional, even occasionally during winters; (xxvii) maintain your car's battery; (xxviii) seal a leaky radiator; and (xxix) dilute your coolant [1].

\section{Vehicle service procedure}

Additionally one

have observed that licensed car carrier facilities undertake pos itive processes for the duration of the carrier of a vehicle. In this session, we will talk about the frequent things to do carried out in the carrier center. One of the most vital phase is job card and its filling procedure.

\section{Common Activities in the Workshop}

(i) Job card and its filling procedure

(ii) Washing of vehicle and Washing Procedure

(iii) Engine minor tune up

(iv) Oil replacement

(v) Checking of battery - electrolyte level and top-up

(vi) Clutch and brake-free play and their adjustment

(vii) Lighting system, its various parts and their checking

(viii) Identification of greasing points of wheelers and procedure of greasing

(ix) Checking of tyre inflation and procedure of inflation [1].

\section{Job Card and Its Filling Procedure}

When a car proprietor enters the carrier center, he or she is attended by means of the supervising engineer. The consumer informs about the automobile defect. After getting comments from the automobile proprietor or driver related to defects of the vehicle, the supervising engineer in a provider station or workshop inspects it. The defects pointed out or listed are stated down in a general format, which is known as the job card or work order. In order to point out his pleasure with the prognosis made with the aid of the supervising engineer, the client of the automobile symptoms the job card earlier than the repairs on the car are started. Work is then assigned to the worried individual to lift out repairs and the supervisor signs and symptoms the job card too. The work order or job card is organized replica [1]. Motor motors want to be frequently maintained and repaired when essential in order to make certain vehicular health, toughness as properly as human and car safety. Globally thousands and thousands of motors are produced annually. These automobiles want preservation and restore as the want can also be. Statistics exhibit that, in the US, over $75 \%$ of all jobs, of which the motor car maintenances and restore is an quintessential part, is in the offerings sector. The carrier quarter additionally creates over $85 \%$ of newly-created jobs in the U.S. Over $60 \%$ of the Gross National Product (GNP) of the U.S is similarly generated via the offerings sector. In creating nations such as Brazil 54.5\% of GNP is generated via the offerings region (Cauchick, Miguel Salomi, 2004). In Malaysia, about $58 \%$ of financial things to do in phrases of cost are from the offerings area (Elistina \& Naemah, 2011). The motor car enterprise in South Africa offers with over 30 manufacturers on the market and over one thousand mode versions (Anon, 2006). Foster (2006) then again reordered forty two manufacturers in South Africa with over 1200 mannequin variants, developing 10,000 jobs. The motor automobile enterprise in South Africa consequently contributes about 7.6\% to the GNP of the USA [2].

The gadget of preservation and restore works randomly, with overload or below load, violating techniques - selection rules. A specific challenge in making choices is due to the reality that in the passenger park there are extra than a hundred automobiles of more than a few capacities. The most complicated graph of buses consists of many components of units, units, the carrier nomenclature of which exceeds dozens of operations. In turn, the upkeep and restore complex, the most complicated queuing system, consists of a multitude of subsystems, fashions of regulatory, informational, organizational, technological and monetary support. Therefore, these days it is tough to think about the method of administration and decision-making besides the availability of records applied sciences for digitizing the manifestation of random events, for developing regulatory technologies, accounting and manipulate systems, and technological knowhow to motivate employees to make bigger productiveness and satisfactory of work in the upkeep and restore system. Research and enhancement of methods, strategies of administration and making sure a excessive degree of reliability, durability, safety, and affectivity of MTE and motor motors (MV), which include the use of records technologies, are carried out through scientists from more than a few fields of transport, data applied sciences and different areas. However, the introduction of such administration schemes and software program merchandise aimed at the renovation (prevention) device of the automobiles is instead restrained and as a result, in some enterprises, the report glide is fashioned solely in paper form, which complicates data evaluation tactics [3-9].

The answer for growing overall performance of preservation workshops of cars is represented through developing a correct workshop diagram like that in determine 1 below. The design format of the facility now proceeds specifying the place of automobile hoists, required offerings such as oil reticulation, compressed air supply, water provide and waste oil services. All unique measurements will be mentioned in relation to places of equipment, such as automobile hoists, to allow the correct documentation of electricity and different operational provider needs. The diagram offers you the client, a visible effect of the structure the carrier workshop will take after thinking about all elements preferred to grant the superior end result in the area available. 


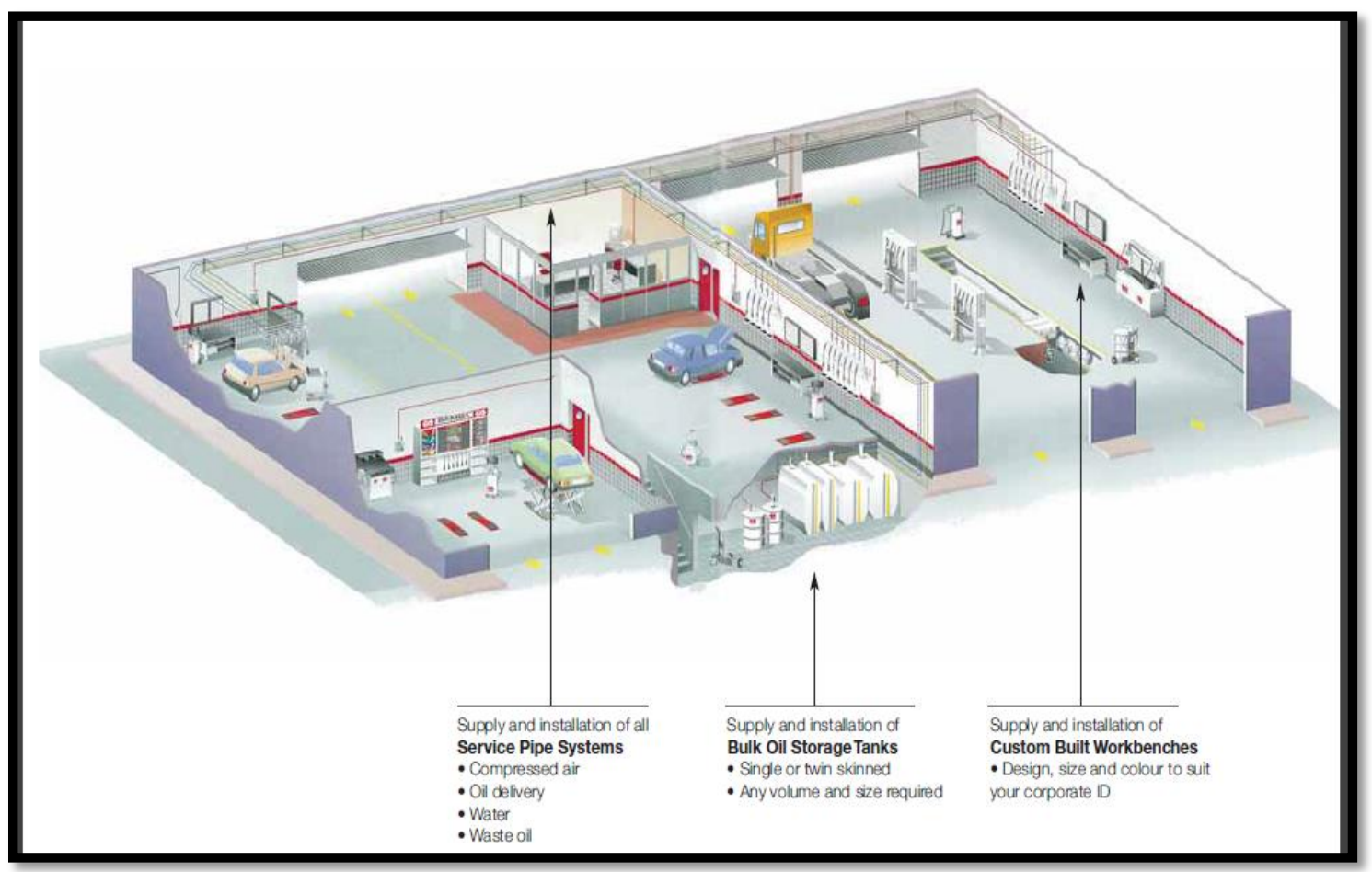

Figure 1: The modern and standard maintenance workshops layout [12]

Additionally, we can furnish a CAD drawing giving a greater full point of view of the layout. The achieved graph sketch is correctly a working drawing to hand over to the builder, electrician, plumber etc. Figure 1 indicates one of the contemporary amenities or workshops design [12]. A devoted hose reel should be used for every kind of fluid, motor oil, equipment oil, compressed air, grease, water, etc. A appropriate manage valve is then related to every hose end. In the case of lubricants, manipulate valves consist of a volumetric meter with partial register for controlling the extent of oil delivered at every provider and a totalizer to point out the whole quantity of oil dispensed. Hose reels can be floor, wall or ceiling set up and can additionally be established inside lubrication pits, for convenient get right of entry to greasing factors and tools oil fills. A shut off valve ought to be established between each and every hose reel inlet hose and the fluid distribution line. Other tools to think about in the working region are cell waste oil drainers and cellular devices for the distribution of grease and lesser used lubricants [12]. Layout is an integral part of a Lean Manufacturing and Maintenance Strategy. Meaningful restructuring requires corresponding physical changes in the layout. Conversely, a layout re-design can be the catalyst for re-structuring. A layout project, properly done, can demonstrate the need for change to an organization reluctant to tear itself apart and rebuild.

-Product-Focused work cells

-Focused Plant-Within-Plant Factories

-Reduced Storage \& Handling Space

-Kanban Stock points

-Direct Delivery of Raw Materials

-Integrated Support Areas

\section{Facility Planning Series}

The links below take you to a series of pages that summarize the basics of Facility Planning and Plant Layout. Four fundamental facility elements go into every layout or space plan: (a) space planning units (aka Activity Areas or SPUs), (b) affinities, (c) space, (d) cSonstraints. Levels of
Detail help organize facility planning into manageable subprojects. Each sub-project has a series of tasks that the design team must complete. The tasks and their sequence differ for each level. These levels are: (I) global (Site Location), (II) supra (Site Planning), (III) macro (Building Layout), (IV) micro (work cell/department layout), (V) sub-micro (workstation design), and elements of a plant or facility layout. Every layout has four fundamental elements: Space Planning Units (SPUs), Affinities, Space and Constraints. These fundamental elements apply to any size facility and at any level. Just as a few chemical elements give rise to an infinite number of compounds, the four layout elements and their variations can produce an almost infinite number of factory layouts [10-12].

-SPUs combine with Affinities to form an Affinity Diagram. The Affinity Diagram is an idealized spatial arrangement that eventually becomes a layout.

-Each SPU requires some finite space whether great or small. Space, added to the Affinity Diagram, distorts it into the Layout Primitive.

- Constraints are conditions, assumptions, policies or edicts that restrict the design is some way. For example, "The layout must fit into the existing building." Constraints further modify the spatial arrangement and a Macro- layout results.

\section{Levels of Facility Planning}

Factory layout is the focal point of facility design. It dominates the thinking of most managers. But factory layout is only one of several detail levels. At Strategies, we find it useful to think of facility planning at five levels: (I) global (Site Location); (II) supra (Site Planning); (III) macro (Building Layout); (IV) micro (Work cell/Department Layout); and (V) sub-Micro (Workstation Design). At the Global level, we pick out a website online location. This entails elements such as freight cost, labor cost, talent availability and web site focus. At the Supra-Layout degree we format the site. This consists . of number, size, and vicinity of buildings. It consists of infrastructure such as roads, water, gasoline and rail. This 
diagram have to seem in advance to plant expansions and eventual web site saturation The Macro-Layout plans every building, shape or different sub-unit of the site. Operating departments are described and positioned at this level. Frequently, this is the most necessary degree of planning. A Macro-Layout group The Micro Level IV determines the region of particular gear and furniture. The emphasis shifts from gross cloth float to private house and communication. Socio-Technical issues dominate. The sub micro degree focuses on person workers. Here we format workstations for efficiency, effectiveness and safety. Ergonomics is key. Ideally, the sketch progresses from Global to Sub-Micro in distinct, sequential phases. At the stop of every phase, the plan is "frozen" by way of consensus [12, 13, 15]. Layout is complicated by multiple often competing objectives such as minimize investment in equipment, minimize overall production time, provide for employee/customer convenience, maintain flexibility of arrangement/operation, minimize material handling cost, utilize existing space most efficiently, and can have a huge effect on productivity $[12,14]$

\section{Methodology}

The data is collected from a random vehicle large workshop (Rashad maintenance workshop-Swaieleh-Jordan), it executes maintenance works randomly, it presents maintenance operations to about 100 automobiles/day, having about 15 technicians). The works of such workshop is random, no queue, no management and no fixed prices for same works. This workshop is disorder has many problems with customers and no regular policy. This study aims to classify and re-layout of the workshop. And also in this work the effects of layout on mean time to repair (MTTR) and faults is studied. One of suggestions studied is to rearrange the studied vehicle maintenance workshop to have 5 departments with the following specifications-Table 1 .

Table 1 Data collected

\begin{tabular}{|l|l|l|l|}
\hline Department & Dept. Name & $\begin{array}{l}\text { Area } \\
\left(\mathrm{m}^{2}\right)\end{array}$ & Tiles \\
\hline 1 & Engine & 8 & 4 \\
\hline 2 & Brake and wheels services & 6 & 3 \\
\hline 3 & Gear & 8 & 4 \\
\hline 4 & $\begin{array}{l}\text { Reception and customer } \\
\text { services and spare parts }\end{array}$ & 4 & 2 \\
\hline 5 & Exhaust and radiator & 6 & 3 \\
\hline
\end{tabular}

\section{Results and discussion}

The task here is to select between many alternatives of layouts. In this study the main base to select the best alternative is MTTR. The best alternative is the layout offers min MTTR. This will be achieved depending on the relation between maintenance department, spare parts location, workers moving between departments and size of departments. For the two following suggested layouts, MTTR is calculated and compared. The dependency of department will be considered as follows: $(1,2): 0.25 ;(1,3): 0.7 ;(1,4): 0.9 ;(1,5): 0.9$; $(2,3): 0.6 ;(2,4): 0.9 ;(2,5): 0.25 ;(3,4): 0.9 ;(3,5): 0.25 ;(4,5): 0.9$. If cars go from left to right the alternative number 1 has more fexibility than two since the reception and customer services is in a good position and so it needs less time to be classified and maintained. The dependency of alternative 1 is: $0.9 * 0.9 * 0.6 * 0.25=0.1215$. The dependency of alternative 2 is $0.7 * 0.9 * 0.25 * 0.9=0.14175$.

\begin{tabular}{|l|l|l|l|}
\hline 5 & 1 & 1 & 3 \\
\hline 5 & 1 & 1 & 3 \\
\hline 5 & 2 & 2 & 3 \\
\hline 4 & 4 & 2 & 3 \\
\hline
\end{tabular}

\begin{tabular}{|l|l|l|l|}
\hline \multicolumn{5}{|c|}{$\mathbf{a}$} \\
\hline 5 & 4 & 2 & 3 \\
\hline 5 & 4 & 2 & 3 \\
\hline 5 & 1 & 2 & 3 \\
\hline 1 & 1 & 1 & 3 \\
\hline
\end{tabular}

Figure 2: $a, b$ the suggested layouts for the workshop

It can be noticed that the first alternative is better since department no. 4 is connected with two adjacent important departments $(+0.1)$, more flexible $(+0.1)$ and having dependency between departments lower than alternative 2 $(+0.1)$ which means that MTTR is lower by $30 \%$ than layout 2 . Figure 3 shows a comparison between the two alternatives depending on MTTR.

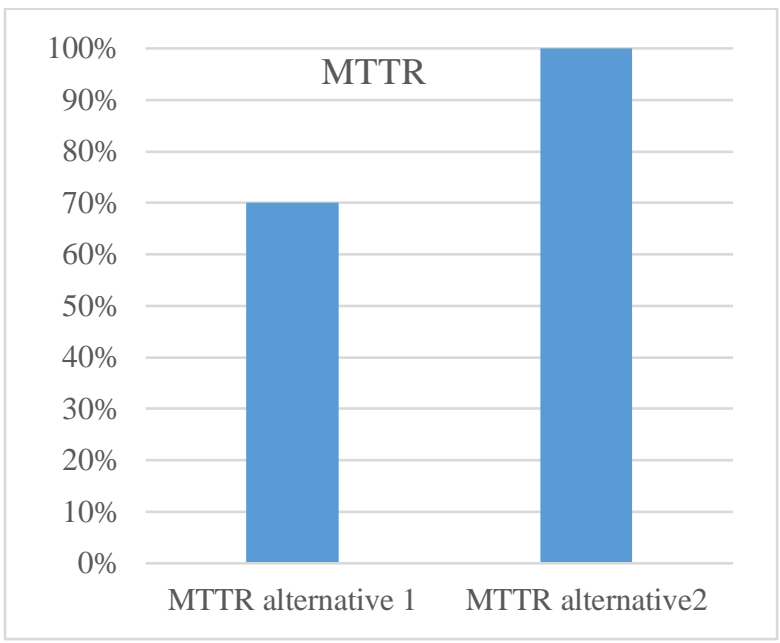

Figure 3: MTTR for layouts alternatives

It can be noticed from figure 3 that MTTR in the case of more accurate and flexible and low dependency layout is better, the vehicles needs lower time for maintenance and repair.

\section{Conclusions}

Layout and facility planning play a vital role in improving automobiles maintenance operations, the better layout of the workshop improving maintenance operations by reducing MTTR and quality of maintenance and also costs.

\section{Ethical issue}

Authors are aware of, and comply with, best practice in publication ethics specifically with regard to authorship (avoidance of guest authorship), dual submission, manipulation of figures, competing interests and compliance with policies on research ethics. Authors adhere to publication requirements that submitted work is original and has not been published elsewhere in any language.

\section{Competing interests}

The authors declare that there is no conflict of interest that would prejudice the impartiality of this scientific work. 


\section{Authors' contribution}

All authors of this study have a complete contribution for data collection, data analyses and manuscript writing.

\section{References}

[1] CLASS IX. AUTOMOTIVE SERVICE TECHNICIAN -Germany. 2019.

[2] Bulgakov NF, Kovalenko VV, Gorbaneva AV, Shalimov SN. Management of preventive maintenance of vehicles. InIOP Conference Series: Materials Science and Engineering 2019 Oct (Vol. 632, No. 1, p. 012074). IOP Publishing.

[3] Bulgakov N F, Burkhiev TS. Quality management protection MV. Modeling and optimization (Krasnoyarsk: KGTU). 2002:164

[4] Bulgakov NF, Kovalenko VV. Information support technology in the vehicle prevention regulations J. of the Siberian Federal Univ. Ser.: Eng. and Technol. 2013;6(2):203-210

[5] Postolit AV, Vlasov VM, Yefimenko DB. Informatsionnoye obespecheniye avtotransportnykh sistem [Information support of motor transportation systems]. Moscow, MADI Publ. 2004.

[6] Sushchev AA. Improving the quality management of car service based on the application of new information technology, Dissertation. 2010.

[7] Senra P, Lopes I, Oliveira JA. Supporting maintenance scheduling: a case study. Procedia Manufacturing. 2017 Jan 1;11:2123-30.

[8] Okoh C, Roy R, Mehnen J. Predictive maintenance modelling for through-life engineering services. Procedia CIRP. 2017 Jan 1;59:196-201.

[9] Schuh G, Jussen P, Optehostert F. Iterative Cost Assessment of Maintenance Services. Procedia CIRP. 2019 Jan 1;80:488-93.

[10] Bulgakov NF, Kovalenko VV, Gorbaneva AV, Shalimov SN Management of preventive maintenance of vehicles. InIOP Conference Series: Materials Science and Engineering 2019 Oct (Vol. 632, No. 1, p. 012074). IOP Publishing.

[11] Bulgakov NF, Kovalenko VV, Sirenko LN, Sysoev MA. Model of statistical evaluation of the characteristics of reliability and efficiency Certificate of computer program registration. 2007;20067613059.

[12] Alemlube reports. Automotive Workshop Design Equipment Installation. Australasia. 2018

[13] Ahmad I, Ahmad S. The Mediation Effect Of Strategic Planning On The Relationship Between Business Skills And Firm's Performance: Evidence From Medium Enterprises in Punjab, Pakistan. Opcion. 2019;35(24):746-78.

[14] Ahmad I, Ahmad S. Multiple Skills and Medium Enterprises' Performance in Punjab Pakistan: A Pilot Study. Journal of Social Sciences Research. 2018; Special, (4):44-9.

[15] Ahmad, I., Sahar. Waste Management Analysis From Economic Environment Sustainability Perspective. International Journal Of Scientific \& Technology Research. 2019; 8(12), 1540-1543. 